\title{
Oil and Gas Well Brines for Dust Control on Unpaved Roads - Part 2: Environmental and Health Impacts
}

\author{
Bryce F. Payne, Jr., PhD
}

Independent consulting soil and environmental scientist since 1992. Director of Science and Technology, Gas Safety Inc. Affiliated consultant, Collaborative Laboratories for Environmental Analysis and Remediation, University of Texas at Arlington

Doi: 10.19044/esj.2018.v14n30p166 URL:http://dx.doi.org/10.19044/esj.2018.v14n30p166

\begin{abstract}
Natural gas and oil drilling have expanded rapidly in the U.S in recent years. The volume of various associated waste products has been increasing. One such waste product is the typically saline water produced from the wells along with the hydrocarbons. A variety of methods are currently being employed to dispose of this oil and gas well brine (OGB). One such practice is spreading OGB on unpaved roads for dust control and road stabilization. This investigation focused on the likely effectiveness and anticipatable risks of spreading OGB on unpaved roads. Despite decades of regulated use of OGB for dust control, there appears to be a complete lack of data indicating the practice is effective. Analysis of regulations, related literature, and original data indicated, as previously presented in Part 1 (Payne, 2018), that spreading OGB on unpaved roads is ineffective and likely counterproductive for dust control and road stabilization, and presents numerous potential and immediate environmental and health risks as discussed in this Part 2.
\end{abstract}

Keywords: Oilfield brine, produced water, dust suppression, dust control, unpaved roads, oil and gas wastewater disposal, environmental impacts, health impacts

\section{Introduction}

\section{Oil and gas well brine and its disposal}

It is not common knowledge that oil and gas wells typically produce substantially more water than oil or gas, usually less water earlier, and increasingly more later in the production life of a well (Conselman, 1967: Moritis, 2004; Veil et al., 2004). That water must be separated from the hydrocarbon product stream before the product is transported. 
Produced water typically has a high salt content, mostly sodium chloride, and is consequently also referred to as oil and gas well brine (OGB). Once separated, the OGB is a waste. Conventional gas wells produce somewhat less wastewater than conventional oil wells. Horizontal wells typically produce more wastewater per unit of production than vertical wells, and wells stimulated with hydraulic fracturing typically produce more than their conventional counterparts. It has been reported that before 2000, nearly no U.S. oil wells were hydraulically fractured, but $51 \%$ of oil produced in the U.S. in 2015 came from hydraulically fractured wells (USEIA, 2016). Consequently, oil and gas well wastewater production will likely increase along with the management challenge it presents.

Numerous practices have been used to manage oil and gas well wastewater (Veil et al., 2004). Among such practices are deep-well injection, evaporation, and various treatment methods followed by recycling for use in oil and gas wells and other industrial processes. One of these, due to the typically elevated salt content, is to apply OGB to paved roads as a winter deicer and to unpaved roads as a summertime dust-control and stabilization agent. Though less important than some other methods of disposal with respect to total amount of wastewater involved, application on roadways is common and locally important in some areas, including at least the states of Michigan, New York, Ohio and Pennsylvania.

\section{Studies on the application of OGB to unpaved roads for dust control}

Herrold (1984) concluded application of OGB to unpaved roads seems to date back to early development of the oil and gas industry in Michigan. Similarly, the Pennsylvania Department of Environmental Protection (PaDEP) Environmental Quality Board (2016) stated, "Throughout the history of conventional oil and gas development, brine has been beneficially used in dust suppression and road stabilization activities on dirt roads..." Despite that OGB has reportedly been applied to unpaved roads for dust control since the early days of the oil industry, the literature on such of OGB is sparse. A search for discoverable literature on science or engineering measurements of the actual effectiveness of OGB for dust control found only four such reports, two of which could only be accessed indirectly, and only one of which was published less than 36 years ago (Moore and Welch, 1977; Moses, 1981; Russell and Caruso, 1982; Graber et al., 2017). Realistically, road application of OGB was primarily an oil-well waste-disposal practice (Herrold, 1984).

In the 1970s, concerns arose that abusive spreading of OGB on land, including roads, was occurring and could impact water quality. Michigan and other states developed rules to regulate use of OGB on roads. Non-compliance and a lack of enforcement, usually due to lack of resources to support 
enforcement, are still common problems that can result in exploitation of roadways as OGB disposal grounds.

As reported in Part 1 (Payne, 2018) at this time there appears to be no actual measurement data that support the use of OGB as an effective dustcontrol agent. There are direct observations of its ineffectiveness (Figure 1.).

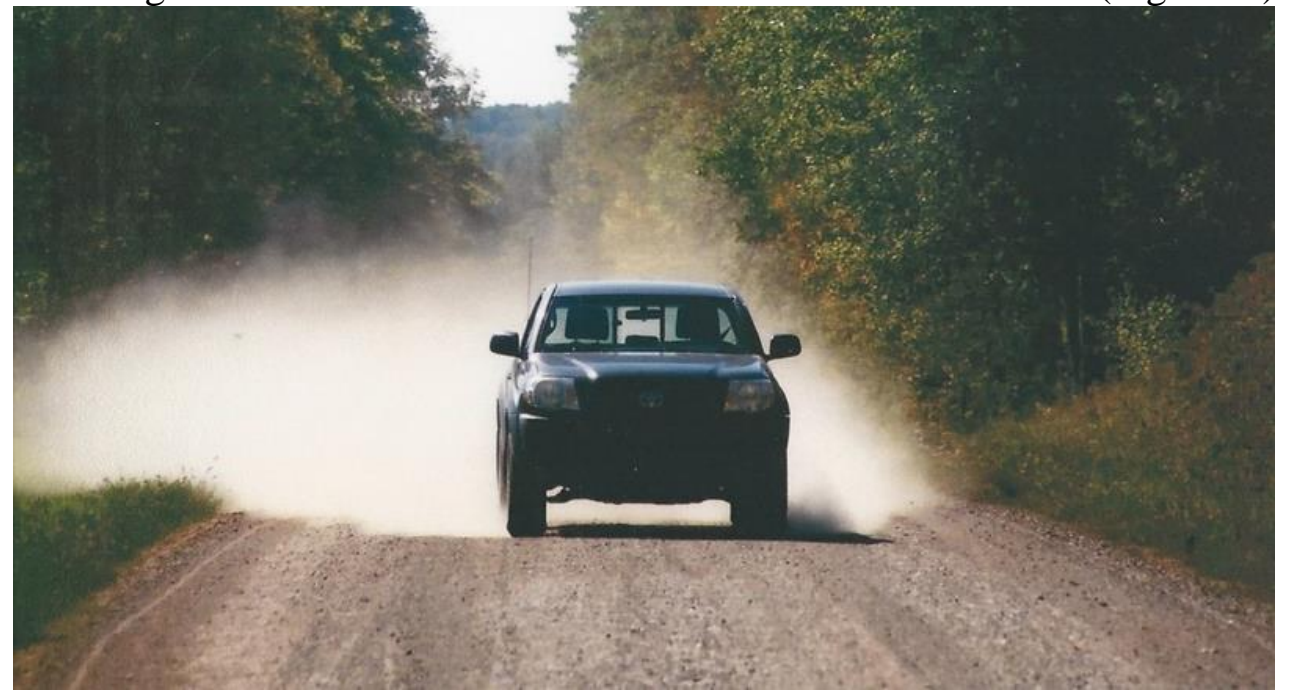

Figure 1. September 2017 dust from unpaved road in northwest Pennsylvania treated multiple times with OGB over the summer, with most recent treatment no more than 6 days and perhaps as recently as several hours before this image was taken (photo courtesy Siri Lawson).

The very limited available data indicates that OGB cannot be effective unless applied at rates several times the maximum rates state authorities consider acceptable in terms of environmental risks. Further, examination of the more thorough literature on commercial chloride dust-control agents clearly indicates there is no reason to expect OGB to be an effective dust control agent. Finally, a conservative cost comparison for dust control, based on OGB compared to a commercial $\mathrm{CaCl}_{2}$ product, showed the use of brine is actually more expensive, without considering the potential need for more road maintenance work if sodium-rich brine is used instead of calcium chloride, and without considering the increased health and environmental risks. This, Part 2, considers some of those health and environmental risks.

\section{Considerations of Some Environmental Risks}

Environmental and health impacts are notoriously difficult to evaluate even when direct evidence is available. Reported or, lacking direct empirical evidence, potential environmental and health impacts can be considered in terms of contaminants, exposure pathways, and likelihood of occurrence. For example, consider a simple comparison of basic requirements of OGB compared to commercial chloride dust control product applications. A typical 
dust season would require at least 4 OGB applications per state guidelines while use of commercial product on the same road would typically require 2. Weather events, vehicle collisions, mechanical malfunction, inadvertent or intentional over- or misapplication and more could cause leakage or uncontrolled delivery to unintended areas. Further, $\mathrm{NaCl}$ and $\mathrm{CaCl}_{2}$ are both close to $60 \%$ chloride by weight, but effective dust control/road stabilization requires twice as much $\mathrm{NaCl}$ as $\mathrm{CaCl}_{2}$ (PaDOT, 2009) and, therefore, use of $\mathrm{NaCl}$ poses a greater risk of chloride contamination. Consequently, considerations as simple as composition and total number of required applications can change risk.

In addition, when direct or reliable, reasonably relevant data are available, there is risk associated with the failure of investigators to adequately explore such data. The PaDEP (1996) investigated the potential for water contamination from OGB applications for dust control at seven locations from 1992 to 1995. Based on the findings and recommendations of that investigation, PaDEP lowered its maximum allowable application rate, clearly indicating that the previous allowable rate had been based on inadequate supporting data. The $1996 \mathrm{PaDEP}$ report contained a brief literature review, which included most of the literature reviewed by the present author. However, the PaDEP review of the literature was neither critical nor thorough, and the report recommended application rates based solely on the subjective opinions of OGB users. Again, risks from OGB applications were underestimated due to a failure to adequately consider available data, and deference to the subjective opinions of OGB users.

\section{Environmental risks of chloride salts}

Chloride is a monovalent anion. Chloride is strongly conserved in environmental waters; once in an environmental water it tends to remain there. Some organisms are particularly sensitive to chlorides. For example, chloride concentrations as low as $400 \mathrm{mg} / \mathrm{L}$ can be harmful to trout and other coldwater fish. The chlorides applied in concentrated form to roads as dust suppressants are readily soluble in water. Consequently, road application of chlorides as a dust suppressant carries a real risk of contamination of waters even at considerable distances from the treated roads (Ramakrishna and Viraraghavan, 2005; Eckstein, 2010).

Calcium and magnesium are essential nutrients for animal and plant life. Nevertheless, excessive levels of these two elements can cause harm, especially to plants, soils, and aquatic ecosystems. Sodium and chloride are so ubiquitous they might not be considered nutrients, but they are essential ions for most forms of life and have fundamentally important interactions with the physical components of the environment, especially soil and water. 
Sodium occurs in nature as a highly water-soluble monovalent cation, which, though not directly toxic in most situations, competes with other cations in environmental and biological processes. If present in excessive amounts relative to other soluble cations, sodium can displace those cations from their functional sites and alter the function of the biological or physical system. Of particular interest with respect to road applications of chlorides, sodium has a particularly troublesome property when present in excess in many soils.

\section{Clay-cation interactions and effectiveness of OGB vs. commercial brine}

[The following discussion is presented in more detail in Section 7 of Part 1 (Payne, 2018).] Certain useful properties of many soils depend on the type and amount of clay minerals present. Briefly, in many soils, the predominant clay minerals belong to a class known as layer alumino-silicates. The three most common layer alumino-silicate clay minerals in soils are kaolins (a form that would be known to some as Fuller's earth), illites (more recognizable forms of which are mica and vermiculite), and smectites (or montmorillonites, a more well-known form of which is called bentonite). Most soil clays occur as colloidal-size particles. All exist as layered crystalline particles, the thickness of which is typically 100 times smaller than the length or width.

All of these layer alumino-silicate clay minerals carry some net negative point charges in their crystalline structure, many of which occur on their outside surface and give rise to cation exchange capacity. These clay minerals retain exchangeable cations in proportions determined by the particular mineral and the relative concentrations of the cations in the water that the clay mineral contacts. The cations held by a clay mineral affect the properties of that mineral, including its physical behavior at the scale of individual particles, bulk properties, and properties critical to structure and performance of unpaved roads (Sullivan and Graham, 1940; Trask and Close, 1957; Bell, 1992; Warrence, Bauder, and Pearson, 2018).

Sodium is a particularly important cation with respect to clay-mineral behavior (Sullivan and Graham, 1940; Trask and Close, 1957; Bell, 1992; Warrence, Bauder, and Pearson, 2018). Clay particles bearing excessive sodium retain more inter-particulate water reducing the bulk strength of the clay, which can lead to liquefaction of clay soils, as in landslides, or, on a smaller scale, a consistency some refer to as "slickness" or "sliminess" of soils, including road soils.

$\mathrm{Ca}$ and $\mathrm{Mg}$ occur as divalent cations and interact with clay particles very differently than sodium. Multivalent cations, like $\mathrm{Ca}$ and $\mathrm{Mg}$, can effectively bond individual clay particles together by linking between cation 
exchange sites on separate clay particles, a structural condition called "cation bridging", which results in an increase in bulk strength.

The effects of monovalent $\mathrm{Na}$ compared to multivalent cations, predominantly $\mathrm{Ca}$ and $\mathrm{Mg}$ in many soils, on the bulk properties in clays give rise to two types of behavior in response to the amounts of such cations dissolved in the water that the clay particles contact. Flocculation/dispersion is important at lower cation concentrations. "Salting out" is important at higher cation concentrations.

The stabilizing effects of "salting out" clays with high salt concentrations are greater than the stabilizing effects of calcium (or magnesium) flocculation of the clays. Nevertheless, it should also be recognized that the flocculating effects of calcium are effective along with "salting out" at high concentrations of $\mathrm{CaCl}_{2}$, and continue after those high concentrations have been depleted. In contrast, "salting out" with $\mathrm{NaCl}$ must overcome the dispersing effect of sodium saturation of the clay charge sites, and that dispersing effect will remain after the high concentration of $\mathrm{NaCl}$ has been depleted. Hence, the better performance of $\mathrm{CaCl}_{2}$ (and $\mathrm{MgCl}_{2}$ ) compared to $\mathrm{NaCl}$ as a dust control agent on unpaved roads is due not only to its stronger deliquescence (see 3.3, below, and Payne, 2018) but also the effects of calcium on clay-aggregate formation and stability, which is supported by the findings of Graber et al. (2017).

Because of the differences in flocculation/dispersion and "salting out" effectiveness of $\mathrm{Na}$ compared to $\mathrm{Ca}$ or $\mathrm{Mg}$, along with related differences in intensity of adsorption of water from ambient air and related crystallization behaviors, and the dominance of $\mathrm{NaCl}$ in $\mathrm{OGB}$, application of OGB for dust control can be reasonably expected to exacerbate dust problems. When applied to the road surface without effective incorporation, as typically done with OGB, sodium chloride solutions will either soften road structure and contaminate surrounding waters in wet weather; or will exacerbate dustiness of the road, while becoming part of the actual dust leaving the roadway under dry conditions. Such entrainment of chlorides in dust from brine-treated roads was confirmed by field investigations of impacts on roadside trees as early as 1936 (Strong, 1944).

\section{Runoff and contaminant distribution: commercial vs. OGBs}

The sodium that moves off or through and out of the road must eventually end up somewhere else. That which leaves the road dissolved in water will move through ditches and drainage-ways to end up in nearby soils, sediments and waterways. As soil and sediment sodium levels increase, vegetation and local water-flow patterns will be impacted. As sodium and chloride levels in waters rise, aquatic life will be impacted. When salt accumulates sufficiently in the soil, animals will use the soil as a salt lick. If 
the salt is associated with toxic contaminants, those animals will be impacted, which raises the issue of toxic contaminants in brine.

Commercial $\mathrm{CaCl}_{2}$ and $\mathrm{MgCl}_{2}$ products typically are evaporites from natural water bodies in closed drainage basins or are industrial products.

Consequently, the commercial products are relatively free of toxic components, or relatively well understood in terms of their toxic components. OGBs, in contrast, are from geological formations where they developed along with petroleum and a related range of toxic components. State authorities that authorize use of OGBs have testing requirements that provide little information on potential toxic impacts. In most cases the only requirement is that a single OGB sample from the source geological formation be analyzed every year to few years. Hence, the actual amounts of toxic compounds delivered by OGBs applied to roads is unknown. The toxic components in OGBs range from dissolved inorganic elements such as lead and arsenic, to toxic petroleum compounds such as benzene, to toxic radioactive species such as radium and uranium. Which and how much of these occur in OGBs depends primarily on the source geological formation.

Poje (1986) developed a toxicological review of composition data for Ohio and Michigan OGBs and concluded that sodium and chloride were the inorganic contaminants of most concern and benzene, due to its toxicity, the organic contaminant of most concern. Poje (1986) pointed out that polycentric (or polycyclic) aromatic hydrocarbons (PAHs) and phenolics are almost certainly present in OGBs and should also be considered with respect to potential environmental and health impacts. The conclusions of Poje (1986) agree with more recent conclusions by others (Irwin et al., 1997; Skalak et al., 2014).

There have been reports on the environmental impacts of applications of chlorides on roads for ice control, fewer about the impacts of commercial brine-spreading for dust control, and far fewer with respect to spreading of OGBs (Farmer, 1993; Norrstrom and Bergstedt, 2001; Goodrich et al., 2009; Nelson et al., 2009; Fayun et al., 2015; Hiki and Nakajima, 2015; Ramakrishna and Viraraghavan, 2015). Most of those reports have focused on impacts on water resources, along with soils and vegetation. Perhaps most telling with regard to implications of the reported impacts is the conclusion of the PaDEP (1996) that the OGB applications rate then being approved ( $1 \mathrm{gal} / \mathrm{sq} \mathrm{yd}$ ) was unsafe. The PaDEP lowered its maximum application rates to the current $1 / 2$ and $1 / 3 \mathrm{gal} / \mathrm{sq}$ yd per month. As a means of evaluating some of the likely environmental impacts of dust emissions from roads treated with OGB, it is helpful to consider from a soil perspective the implications of Poje's (1986) conclusions in terms of foreseeable situations on actual road surfaces receiving typical OGB applications. 
The guidelines of several states set a maximum OGB-spreading rate for dust control on unpaved roads at a single application of OGB at 1/2 (initial application) or 1/3 (follow-up applications) gal/sq yd, applied once per month ${ }^{1}$ during the dust-control season, in most areas late spring through fall. Assume brine will have a sodium chloride concentration around $10 \%$, calcium chloride around 5\%, magnesium chloride around 1\% (Dresel and Rose, 2010; Payne, 2018). For convenience in this discussion, the density of OGB is assumed to be the same as water.

To perform such an evaluation, assumptions are necessary with regard to road conditions at the time of OGB application. Within typical ranges, the practical consequences will be similar regardless of assumed compared to actual road conditions. For well-constructed and maintained roads, the surface material will contain around $4 \%$ to $15 \%$ fines (US Dept. of Transportation, 2015) and will be compacted to a porosity of around 10\% (or less). Assuming $15 \%$ fines, a brine application of $1 / 3 \mathrm{gal} / \mathrm{sq} \mathrm{yd}$ will first saturate the road surface material to a depth of about 0.6 in $(1.5 \mathrm{~cm})$, then drain further to wet perhaps the top 1 in $(2.5 \mathrm{~cm})$. After drainage, about $90 \%$ of the water will be associated with the aggregated soil fines in that wetted surface layer.

What happens to the dissolved salts when the water in the brine evaporates under the summer sun? If evaporation is rapid, some of the salts will be deposited as efflorescence on the road surface. Such salt efflorescences are mechanically fragile and readily soluble in water. The salts in such efflorescences will most likely leave the road as dust or, if they are not blown away as dust, they will be dissolved and washed away in the next rain. Such salt efflorescences will continue to form as long as there is capillary continuity between the actual road surface and the deeper portions of the wetted road surface material. Because most road surfaces are quite warm, even hot, in summer weather conditions, evaporation of the water from the OGB will usually be rapid. The more rapid the evaporation, the less time for deep infiltration, the more rapid the capillary rise and the more salt will end up as efflorescence on the surface, increasing dust from even a well-constructed and maintained road surface.

If the same OGB application were spread during relatively cool and moderately humid weather, brine-water evaporation will be slower, the brine will have time to infiltrate more thoroughly, and less salt-laden water will be drawn by capillary rise back to the surface. Under such circumstances, as previously discussed, which salts are in the brine will contribute to, or weigh against, effectiveness of the OGB as a dust control agent.

\footnotetext{
${ }^{1}$ Bear in mind that almost all state guidelines allow application rates higher than the specified "maximum" rate if dust, weather, traffic or other conditions require higher rates as judged by the local authority or its approved agent.
} 
$\mathrm{CaCl}_{2}$ is a strongly deliquescent salt, which even in solution can draw moisture from the air into the road surface material, thereby preventing airborne release of fine particles (dust). Though it is generally considered that the deliquescence of $\mathrm{CaCl}_{2}$ becomes effective at a $\mathrm{RH}$ of $29 \%$, that deliquescence is actually related to both temperature and humidity, and the deliquescence becomes effective at lower $\mathrm{RH}$ as temperature increases (Kirchner and Gall, 1991). The resulting retention of moisture strengthens aggregates of soil fines, thereby preventing mechanical separation and air suspension of particles as dust under most conditions.

$\mathrm{MgCl}_{2}$ is also deliquescent, but its deliquescence is related only to $\mathrm{RH}$, being effective at $\mathrm{RH}$ above $31 \%$ over the full temperature range of concern for road surfaces. However, the ability of air to hold moisture increases as temperature increases. So, assuming no weather change is occurring, on a typical summer day, the RH will be high in the morning and drop until the daily high temperature is reached. Further, road surfaces are hotter than the air on most summer days. Consequently, the deliquescence of $\mathrm{MgCl}_{2}$ can become less effective as a road-wetting mechanism during some hotter, drier summer days.

$\mathrm{NaCl}$ does accumulate deliquescent moisture from the air, but not until $\mathrm{RH}$ is above $79 \%$. Deliquescence is reversible, that is, a salt wetted by deliquescent water can dry back into a solid. Typically, however, a phenomenon known as hysteresis occurs in the deliquescence wet-dry cycle. That is, the path of accumulation of deliquescent water as humidity increases is not the same as the path of the loss of water (drying out) as humidity decreases. For most deliquescent salts hysteresis is apparent in that drying begins at a humidity lower than the humidity at which wetting begins. In the case of $\mathrm{NaCl}$, loss of accumulated deliquescent water does not begin until the RH drops below 45\% (Wise et al., 2007). On many summer nights, RH rises well above $79 \%$. Roads treated with $\mathrm{NaCl}$ may appear moist in the morning, because the $\mathrm{NaCl}$ in the road accumulated deliquescent water overnight. As the summer sun warms the road surface and air, RH falls relatively rapidly, often below $45 \%$. Consequently, roads on which $\mathrm{NaCl}$ is used as a dust suppressant will be without an effective moisture retention agent during the dustiest hours of many warm days.

\section{Deliquescence and a sodium chloride potential for road destabilization}

Within a matrix of road material, solid salt occurs as individual particles. This is true even for sodium chloride applied as a solution, like OGB, because a single afternoon under typical summer road surface conditions will dry a road sufficiently to crystallize all the sodium chloride in a light application, such as $1 / 3$ gallon per square yard. So, it is helpful to 
consider what likely happens to a typical crystal of a deliquescent salt in a road materials matrix.

As deliquescent water accumulates the salt particle will dissolve. If enough water accumulates, the particle may dissolve nearly completely, becoming a volume of salt water within the soil matrix. If two or more particles are in proximity to each other, the wetted volumes of those particles may contact and become a single wetted volume. When drying begins, a salt crystal will begin to form. If the wetted volumes of previously separate salt particles have merged, the new, larger wetted volume may or may not form salt crystals at the same locations as the originals. If a salt crystal grows at a new location, or crystals grow at new locations, the crystal growth process can force other particles to move as the forces generated during crystal growth can be extreme; recrystallization of some salts is capable of spalling concrete and fracturing rock. ${ }^{52,53}$ Cumulatively over an extensive area, such microscopically small movements within the road material matrix will reduce the mechanical strength of the road.

Calcium, magnesium and sodium chlorides are the three salts of most concern as dust-control agents, and as the major components in OGB. Each of them has its own crystalline properties and conditions for crystallization. Calcium chloride has several different hydration state crystalline forms. However, only calcium chloride hexahydrate $\left(\mathrm{CaCl}_{2} .6 \mathrm{H}_{2} \mathrm{O}\right)$ is stable under the conditions found on most roads. Further, at typical summer temperature and humidity conditions, each calcium chloride (hexahydrate) crystal exists within a surrounding volume of deliquescent water. Consequently, roads with enough incorporated $\mathrm{CaCl}_{2}$ will rarely "dry out" under summer environmental conditions. In fact, one of the disadvantages of $\mathrm{CaCl}_{2}$ as a dust-control agent is that roads can actually become too wet if humidity is too high for prolonged periods. $\mathrm{MgCl}_{2}$ wetted by deliquescence can begin to dry out when temperatures get high enough, but it remains an effective wetting agent on unpaved roads under the environmental conditions that occur in many locales, with less tendency to become too wet under prolonged high humidity conditions.

As discussed in the previous section (3.3), under most common environmental conditions, the drying behavior of $\mathrm{NaCl}$ is different. Because of hysteresis in the wet-dry cycle of $\mathrm{NaCl}$, while accumulation of deliquescent water does not begin until RH goes above $79 \%$, loss of the deliquescent water accumulated by a $\mathrm{NaCl}$ crystal does not begin until $\mathrm{RH}$ drops below about $45 \%$. Nevertheless, once the drying begins, it can progress rapidly, along with regrowth of the $\mathrm{NaCl}$ crystal. If the newly formed $\mathrm{NaCl}$ crystals are of a different size, shape or location than the original sodium chloride particles, resultant physical movements within the road matrix and road weakening can be expected. Such shifting of particles, even on a microscopic scale, weakens 
the road surface, which makes mechanical fragmentation by traffic more likely. Mechanical fragmentation generates dust, emission of which results in loss of fines, which results in further mechanical weakening of the road. That is, surface application of any amount of dissolved or solid $\mathrm{NaCl}$, even to wellconstructed and maintained roads, can contribute to initiating a set of mutually reinforcing processes that can initiate and propagate road destabilization and dust emissions (see 3. in Part 1, Payne 2018).

\section{Application to poorly maintained roads exacerbates problems}

Now, the situation is more complicated and the effects of all these salts are destructive when surface applied to a poorly maintained road. As an illustration, consider a road otherwise in apparently fair condition, but which has already accumulated a surface layer of float, i.e., loose road material, including fines. Let us assume for this discussion that the fines content of the float is the same as the road surface soil. This is not likely, in that if the float is present due to pumping of fines to the surface under wet conditions, then the float will be heavier in fines, but, if fines have been blown out of the float under dusty dry conditions, then the float will be lower in fines than the intact road surface soil. Nevertheless, for present purposes, this assumption provides a reasonable approximation of the average, or at least the starting conditions when material is first loosened on the road surface.

Since the float material necessarily resides on the surface of the road, any surface-applied brine will first encounter the float layer. Applying the same conditions used in the preceding discussion of salts in well-constructed and maintained roads, the road soil contains $15 \%$ fines that have a water holding capacity of $30 \%$ (by volume). Again, as previously, since most of the water holding capacity of road soil is in the fines, once the float has been drained by gravity, $90 \%$ of the applied brine in the float will be retained in the fines. When the road surface dries to the point of releasing dust, that dust will be nearly entirely composed of fines that separate from the road surface and suspend in the air. Given the foregoing, and using a brine composition based on an average western Pennsylvania oil brine ${ }^{29}$, i.e., $12 \% \mathrm{NaCl}, 5 \% \mathrm{CaCl}_{2}$, and $1 \% \mathrm{MgCl}_{2}$, one can perform a relatively simple calculation to obtain a rough estimate of the salts content of the dust coming off the brine treated road:

$$
W_{N a}=\frac{V_{N a} \times V_{B}}{\rho_{d}}
$$

where $W_{\mathrm{Na}}$ is $\mathrm{NaCl} \%$ (wt) in dust, $V_{\mathrm{Na}}$ is $\mathrm{NaCl} \%$ (wt/vol) in brine, $V_{\mathrm{B}} \%$ (wt/vol) brine in fines, and $\rho_{\mathrm{d}}$ is the dry density of dust in $\mathrm{g} / \mathrm{ml}$. Using $V_{\mathrm{Na}}=(12 \mathrm{~g} \mathrm{NaCl}) /(100 \mathrm{ml}$ brine $)=12 \%, V_{\mathrm{B}}=(30 \mathrm{ml}$ brine $\left.) /(100 \mathrm{ml}) \mathrm{dust}\right)=30 \%$, and $\rho_{\mathrm{d}}=(1.3 \mathrm{~g} \mathrm{dust}) /(1 \mathrm{ml}$ dust $)$, we find $W_{N a}=2.8 \% \mathrm{NaCl} / \mathrm{dust}$. 
Making the same calculation for calcium and magnesium chlorides yields concentrations in the dust of around $1 \% \mathrm{CaCl}_{2}$ and $0.2 \% \mathrm{MgCl}_{2}$, and therefore a total salts concentration of around $4 \%$ by weight. The bulk density of dust was assumed to be 1.3 , but might range from 1 to around $2 \mathrm{~g} / \mathrm{ml}$. Use of the more extreme densities would increase or decrease the concentration of salts in the dust, thus the concentrations would range from $2.5 \%$ to $5 \%$ by weight; a range for which any value would be an environmentally appreciable amount of salts, consistent with the previously mentioned tree impacts reported by Strong (1944).

It is worthwhile to consider that there are factors that would increase the estimated salt concentrations. In particular, upon saturation with applied brine, the bulk geometry of the fines may lose hydraulic contact with the underlying intact road surface. When this occurs, the fines will be wetter, i.e., have a higher OGB content when they begin to dry to dust, which would increase the salt concentration in the dust into the range of $4 \%$ to $8 \%$ by weight.

The fines may also accumulate on and seal the road surface, resulting in ponding of the brine on the surface. Drying of ponded brine over saturated fines would result in formation of efflorescence salt crystals along with salt crystals associated with the dust particles, further increasing the salts concentration in the dust.

So, for the likely range of conditions on a poorly constructed and maintained road with float materials on the surface, and to which OGB is applied for dust control, the dust released from that road can be expected to have a soluble salts concentration of something in the range of $2 \%$ to over $8 \%$. Further, since the assumption was that the fines concentration in the float was the same as in the intact road soil, the same calculation applies for dust derived from release of the fines from the intact road soil as well. Hence, until there is a weather event (rain, wind) that removes soluble salts, the dust from brinetreated roads, whether well maintained or not, will contain soluble chloride salts concentrations in the range of $2.5 \%$ to potentially over $8 \%$.

Dust bearing such soluble salt concentrations can be expected to have environmental and health impacts. For example, if airborne dust with such salt concentrations settled upon vegetation, it would result in substantial osmotic stress on leaf tissue, recalling again the observations of Strong, ${ }^{40}$ who also reported that runoff from roads receiving brine killed vegetation. So, even as early as 1936, the potential for environmental impacts on both air (dust) and water due to the use of OGB for dust control had been recognized.

\section{Environmental risks of dust}

As previously mentioned, water, soil and vegetation impacts from road spreading of brines, especially for ice control, have received some attention 
(Farmer, 1993; Sanders and Addo, 1993; Norrstrom and Bergstedt, 2001; Goodrich et al., 2009; Nelson et al., 2009; Eckstein, 2010; Fayun et al., 2015; Hiki and Nakajima, 2015; Ramakrishna and Viraraghavan, 2015; among others), but not so for the dust impacts of OGB spreading. The general health and environmental risks posed by dust pollution from unpaved roads that do not receive dust control treatments are now becoming more widely recognized (Greening, 2011). It follows that elevated levels of contaminants, like soluble salts in dusts from OGB-treated roads, can be reasonably expected to increase those risks.

The lack of attention to the anticipatable additional risks posed by exposure to dust from OGB treated roads may have a plausible explanation. If one accepts the premise that applying OGB will control dust, then it follows that dust is controlled and, therefore, air pollution by released dust may be disregarded. As previously discussed, however, there is, in fact, no reason beyond a traditional belief to accept the premise that spreading OGB for dust control is, or under practical conditions is ever likely to be, effective.

\section{Concentrations of other contaminants in dust from OGB-treated roads}

The chloride salts that OGB shares with commercial dust-control products are its predominant, but not its only constituents. OGBs contain a wide range of constituents, but there is a currently limited list of troubling constituents present at levels of potential concern. That short list includes petroleum hydrocarbons, typically DRO (diesel range organics), which include PAHs (polycyclic aromatic hydrocarbons) and BTEX (benzene, toluene, ethyl benzene, and xylenes), along with bromide, iron, manganese and radioactive isotopes of some elements, typically radium. Except to a limited degree for BTEX, these contaminants of concern are functionally nonvolatile under the conditions that would exist following a surface application of OGB containing them. Consequently, the same approach used to estimate salt concentrations in dust from brine-treated roads in 3.5 above can be adapted to estimate likely concentrations of these additional contaminants in the dust.

The following are typical concentrations of OGB components of toxic concern reported by Poje (1986), Dresel and Rose (2010) or determined on samples collected by the present author.

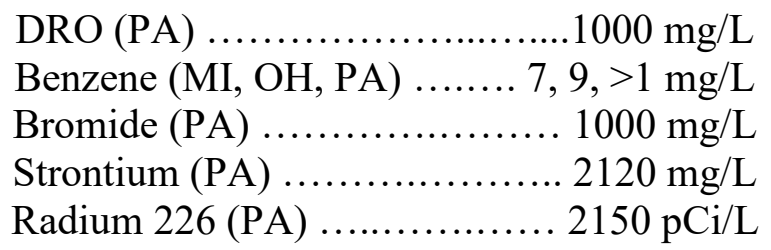


Applying these concentrations in the previous calculation to estimate salt concentrations in OGB-treated-road dust leads to the following likely concentrations of these other contaminants:

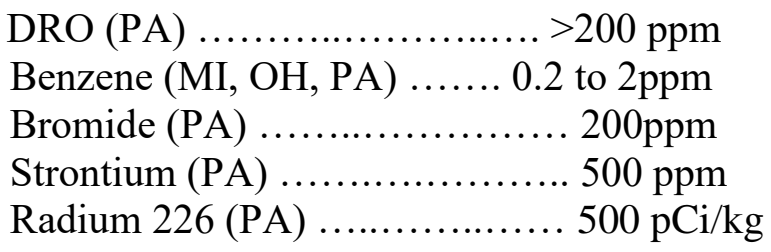

It should be pointed out these concentrations can be expected to become part of the dust on brine-treated roads due to a single application of brine. If, as permitted by the brine-spreading guidelines of various states, the local responsible party concludes that more brine is needed to control dust, then each additional application will increase the concentrations of the contaminants in the brine that will reside in the dust. This contaminant accumulation effect will be countered by two factors, traffic and weather, which interact.

\section{Impact of contaminants on adjacent soil, water, structures, vehicles}

Rain events of sufficient intensity or duration wash some or all these contaminants, or the dust bearing these contaminants, from the road surface, delivering them to adjacent soils and waters. Upon wetting by rain, the dust on the surface of an OGB-treated road will become mud, which will be thrown by passing vehicles onto adjacent vegetation, structures, and the vehicles themselves. Portions of the mud will adhere to the contacted surfaces, the adhesiveness of the mud increasing with the sodium saturation of the clays present. Once attached to a surface, the previously described wetting/drying process that occurs on the road surface will occur in the now attached OGBtreated road dust mud. The $\mathrm{NaCl}$ will dry and form crystals that will bond the mud together, while the $\mathrm{CaCl}_{2}$ and $\mathrm{MgCl}_{2}$ will cause the bonded mud to retain moisture. Such circumstances can be expected to lead to corrosion of affected metal surfaces and osmotic and mechanical stress as well as light, and potentially air, deprivation of contacted plant tissue. Further, the deleterious effects (already discussed) of spreading of Na-rich brine on structural integrity of most unpaved roads will exacerbate the amount of mud released by the road, compared to the same road without OGB treatment.

The counterpart to rain is dry weather. Every summer rain will, sooner or later, be followed by hot, dry conditions giving rise to, or anticipation of, renewed dust emissions. The response will be more OGB spreading. The cycle will repeat, increasing contaminants in the road surface fines, and affected waters and soils. 
There is no reason to expect OGB spreading to provide any better dust control than spreading plain water under any road conditions (see Jones et al., 2013, Graber et al., 2017, and previous discussion). There is reason to believe most OGB is spread on roads that are not properly prepared for chloride-based dust control. Due to the impacts of sodium on most soils, including most road soils, spreading OGB will actually increase the total cumulative dust emitted and eventually weaken the road base. In addition, OGB spreading necessarily loads the road surface and the dust that comes from it with contaminants, which will have environmental impacts. Despite this situation, the potential impacts of dust from brine-treated roads seems to have received nearly no interest or serious consideration, especially potential health impacts.

\section{Human health impacts of dust from OGB-treated roads: expectations}

Although health impacts exposure to road dust are cited in many roaddust control documents (Gesford and Anderson, 2007; Jones et al., 2013; Barnes and Connor, 2014; McHattie, 2015; Aleadelat and Ksaibati, 2017), quantitative information is rare or weakly developed. Some of the available quantitative information has been reviewed and summarized by Greening (2011). Inspirable particles with aerodynamic diameters of $5 \mu \mathrm{m}-10 \mu \mathrm{m}$ that enter the upper airways are filtered out by the upper airways tissues. Particles less than $5 \mu \mathrm{m}$ can pass through the upper airways and travel into the lungs coming to rest in the bronchioles and alveoli. It is reasonable to assume that all insoluble inorganic particles that contact respiratory tissues have some irritating or injurious effect. The severity of the irritation can vary by the type of particle inhaled, with the well-known severe long-term injury and disease due to inhalation of asbestos particles and the minimal impacts of other mineral particles, such as zeolites, which have been proposed as carriers in formulations of inhaled medications. Soluble inorganic particles, e.g., sodium, calcium or magnesium chloride crystals, can be expected to cause localized osmotic tension on the contacted tissue. Toxic contaminants may be present in the dust as chemically and physically distinct particles, or attached to the more typical dust particles derived from local road soil material. Particles $<1 \mu \mathrm{m}$ in size can pass through the walls of the alveoli directly into the circulatory system where they can travel to impact other organ systems (Barnes and Connor, 2014).

Given the small size of the OGB-treated-road dust particles that will contact respiratory tissues, any irritation or injury will be localized near the point of attachment. None of the contaminants at the concentrations present in brine road dust would be expected to result in disease if a sufficiently limited number of such particles contacted respiratory tissues. It may be the case, however, that due to the intimacy of contact with the tissue and the potential for multiple simultaneous stresses, i.e., toxic, osmotic, and 
mechanical, at the contact point, the likelihood of injury may be greater than expected for similar dust particle exposure without the additional coincident stressors associated with dust particles from OGB-treated roads.

For any dust the occurrence and severity of respiratory disease can be expected to increase as exposure increases (ATSDR; University of Nebraska Environmental Health and Safety, 2003; Wyatt et al., 2008; Ghio et al., 2014; Dehghani et al., 2017; Di et al., 2017; ). It also seems reasonable to presume that as the concentrations of high-risk contaminants increase, or the number and concentrations of contaminants generally increase, as in dust from OGBtreated compared to untreated roads, the amount of dust exposure needed to cause disease will decrease. Unfortunately, there is not sufficient information to directly estimate additional risk from the contamination of road dust due to application of OGB.

Given the lack of numerical risk information, an alternate approach is needed to evaluate potential health risks of OGB-treated-road dust. One such approach is to consider how the likely contaminant levels in OGB-treated-road dust compare to currently accepted limits for soil contaminants. Acceptable soil contaminant levels are often referred to as cleanup or action levels because they are often applied on sites where environmental contamination has occurred and cleanup is required. Typically, action or cleanup levels are derived from modeling of potential pathways for toxic exposure, including inhalation. There are differences among authorities with regard to soil cleanup levels, but as a matter of convenience this discussion will start with the PaDEP1993 cleanup levels for diesel-contaminated soils (PaDEP, 1993).

The 1993 PaDEP diesel cleanup standards were based on the determination of total petroleum hydrocarbons as diesel-range organics (DRO) in soil, and required cleanup to $\leq 10$ ppm DRO. DRO is an appropriate comparison for OGB-treated road dust because most of the petroleum hydrocarbons remaining in OGB are DRO due to losses of more volatile petroleum hydrocarbons during storage and handling of OGB. In 1993, the PaDEP had concluded that cleanup to $10 \mathrm{ppm}$ DRO would render a contaminated soil safe. The likely DRO concentration in dust from a road after a single application of an average OGB is $\geq 200 \mathrm{ppm}$ (see 9.1 above), which is $\geq 20$ times higher than the level the PA DEP considered safe in 1993 . Under hot, dry, low-wind summer conditions, multiple OGB applications could occur on the same road. Some OGBs have higher than average DRO concentrations. If used under such summer conditions, the OGB-treated-road dust would likely have DRO levels a hundred or more times greater than the 1993 PA DEP cleanup level.

More recently, cleanup levels have been based on specific contaminants of toxic concern, such as benzene. Prior to soil contact, benzene is a relatively volatile hydrocarbon. Consequently, the benzene contents of 
OGB are relatively low, ranging from 1 to $9 \mathrm{mg} / \mathrm{L}$ in the Michigan, Pennsylvania, and Ohio OGBs previously cited. Nevertheless, due to the toxicity of benzene, especially with regard to cancer, these levels cannot be regarded as trivial. Further, dust from an unpaved road that has received a single application of OGB can be expected to have benzene concentrations in the range of 0.2 to $2 \mathrm{ppm}$. The PaDEP cleanup level for benzene in soils to be reused on-site at underground storage tank (UST) sites is $0.5 \mathrm{ppm}$ (PaDEP, 2012), and the limit for clean fill is $0.13 \mathrm{ppm}$ (PaDEP, 2010). Hence, it is reasonable to expect that dust from a road after a single summertime OGB application can exceed the current PaDEP UST soil cleanup standard, and all will exceed the PaDEP limits for clean fill.

Another group of related toxic compounds are the polycyclic aromatic hydrocarbons (PAHs), which include compounds like naphthalene, pyrene, and anthracene. In diesel fuel, typical total PAHs appear to be in the range of 1 to several percent by weight, i.e. 10,000 to perhaps 70,000 ppm (Irwin et al., 1997; Stogiannidis and Laane, 2015). Naphthalenes (including methylated forms) are the most common PAHs in diesel fuel, and by extension presumably in DRO. It is reasonable to assume a low-end typical level of only non-methylated naphthalene is around $1000 \mathrm{ppm}$. Applying the previous calculation for estimating the concentration of contaminant to be expected in dust from a road following a single application of OGB (see 3.5 and 4.1 above), one finds the estimated concentration of naphthalene to be around 20 ppm. Referring again to the PaDEP UST site closure requirements (PaDEP, 2010), one finds the action (cleanup) level for naphthalene to be $25 \mathrm{ppm}$. It then follows that if there are 2 or more applications of OGB, a definitively toxic contaminant can be expected to be present in the dust at levels above those considered acceptable (for reuse of soil on UST closure sites). In addition, there are numerous other PAHs in DRO that are regarded as somewhat less toxic than naphthalene, but the presence of which can be regarded as further increasing the health risk of exposure to PAHs in dust from roads treated with OGB for dust control.

It is generally accepted that some OGBs contain radioactive contaminants, especially radium. It has also been, in effect, contended that the safety of road spreading of OGB has been established by a lack of historical recognition of impacts. This rationale ignores that, in the data of Dresel and Rose (2010), 5 of 6 western PA OGBs tested contained substantial amounts of $\mathrm{Ra}$, with an average concentration of 2,150 pCi/L (picoCuries per liter, about $80,000 \mathrm{~Bq} / \mathrm{m}^{3}$ ); similar levels having been reported by others (Rowan et al., 2007). Again applying the dust contamination estimate calculation, one application of OGB would increase the Ra concentration by $0.5 \mathrm{pCi} / \mathrm{g}$ in the road dust. Naturally occurring soil Ra levels in PA have been reported in the range of 0.5 to $2 \mathrm{pCi} / \mathrm{g}$ (Greeman et al., 1999). In a laboratory simulation of 
multiple PA OGB applications with intervening rain events, Tasker et al. (2018) recently found that $\mathrm{Ra}$ increased effectively in accord with the preceding estimate up to around $2 \mathrm{pCi} / \mathrm{g}$, with no further increase from additional applications. This finding suggests three implications. (1) Soils in western PA would seem to have an inherent Ra retention limit of $2 \mathrm{pCi} / \mathrm{g}$, provided there are adequate rain events following each OGB application. (2) $\mathrm{Ra}$ applied in brine but not retained in soil is lost to runoff/leaching to contaminate local water and soil, as suggested by findings of Lauer et al. (2018). (3) Repeated OGB applications with insufficient intervening rain events, as in the dry summer weather most likely to cause dust and increased applications of OGB, will likely result in Ra concentrations in dust exceeding $2 \mathrm{pCi} / \mathrm{g}$, perhaps substantially. Because of its carcinogenic hazard, every incremental increase in radiation exposure is regarded as an increase in risk. Consequently, an additional $0.5 \mathrm{pCi} / \mathrm{g}$ in road dust for a single application of OGB is a substantial increase in radiation exposure risk. Tasker et al. (2018) also explored available data and concluded that by far the largest release of radium into the environment by the oil and gas industry in PA is from the road spreading of OGB for dust control.

The U.S. Environmental Protection Agency (EPA) has established a Ra cleanup level of $5 \mathrm{pCi} / \mathrm{g}$ for Superfund sites (Luttig and Weinstock, 1998). This is substantially higher than occurs in PA soils or found by Tasker et al. (2018) in lab-simulated OGB applications, though higher levels likely occur in dust from roads repeatedly treated with OGB. Nevertheless, with regard to risk, it is important to recognize the $\mathrm{Ra}$ cleanup level was based on the assumption that exposure would be due to remote release of gamma rays from radium in a surface soil, not inhalation of Ra-bearing dust (Luttig and Weinstock, 1998). It seems likely such Ra levels would present greater risk when present as dust retained in the airways than as soil underfoot.

Anticipatable levels of toxic contaminants added to road dust by a single application of OGB are at, or well above, relevant cleanup levels. It is reasonable, therefore, to conclude health risks are appreciably increased by exposure to dust from OGB-treated roads. Further, there are other biologically offensive or toxic organic and inorganic contaminants in OGB that have not been addressed in this report, but will also accumulate in the dust on OGBtreated roads. So, the toxic risks of the contaminants discussed above will be acting in a matrix of other contaminants all of which will be simultaneously active. For those individuals exposed to appreciable amounts of such dust, due either to brief intense or prolonged lower level exposures, one might expect health impacts beyond those of dust from uncontaminated local soils. 


\section{Conclusion on effectiveness and risks of use of OGB for dust control on unpaved roads}

The very limited available data and more thorough related literature clearly indicate OGB is not an effective dust-control agent (Payne 2018) and has verified environmental and foreseeable health risks when applied at rates currently considered acceptable by state regulators, even without considering that enforcement of state OGB application rate limits is rare. Rudimentary analysis indicates the practice is not cost effective, and in many cases will be counterproductive with regard to road stabilization. It is, therefore, difficult to view the use of OGB on unpaved roads for dust control and road stabilization as anything more than a legacy oil- and gas-well waste-water disposal practice with substantial environmental and foreseeable health risks, especially health risks of exposure to dust from OGB-treated roads. Further, it is important to recognize the use of OGB for dust control is an insidious practice in that it is presumed to reduce dust when in most cases it will increase dust, which will lead to the conclusion more OGB is needed. Due to the $\mathrm{Na}$ saturation of road soil after prolonged periods of OGB treatment, it can be anticipated that cessation of the practice will likely result in increased dust and calls for resumption of OGB spreading when that is exactly the wrong course.

\section{Acknowledgements}

Development and preparation of the preceding review and analysis was supported in part by Siri Lawson and by Damascus Citizens for Sustainability. The author acknowledges reviews and comments provided by numerous colleagues. The author declares no conflicts of interest.

\section{References:}

1. Aleadelat, Waleed, and Khaled Ksaibati. 2017. A comprehensive approach approach for quantifying environmental costs associated with unpaved roads dust. Journal of Environmental Economics and Policy. Accessed at https://doi.org/10.1080/21606544.2017.1374214 on 20 February 2018.

2. ATSDR Toxicology Training Manual, Module 2: Routes of Exposure. https://www.atsdr.cdc.gov/training/toxmanual/pdf/module-2.pdf 16 February 2018.

3. Barnes, David and Billy Connor. October 2014. Managing Dust on Unpaved Roads and Airports. INE/ AUTC 14.14, Report No. 4000096. Alaska Department of Transportation--Research, Development, and TechnologyTransfer, Fairbanks, Alaska

4. Bell, Frederic G. 1992. Engineering properties of soils and rocks. Butterworth-Heinemann, Oxford, UK. ISBN 0750604891. 
5. Conselman, Frank B. 1967. Geological Aspects of the Brine Pollution Problem. Society of Petroleum Engineers of AIME. Paper Number SPE 1871.

6. Dehghani, Sharareh, Farid Moore, Behnam Keshavarzi, and Beverley A. Hale. 2017.

7. Health risk implications of potentially toxic metals in street dust and surface soil of Tehran, Iran. Ecotoxicology and Environmental Safety 136 (2017) 92-103. http://dx.doi.org/10.1016/j.ecoenv.2016.10.037.

8. Di, Qian, Yan Wang, Antonella Zanobetti, Yun Wang, Petros Koutrakis, Christine Choirat, Francesca Dominici, and Joel D. Schwartz. 2017. Air Pollution and Mortality in the Medicare Population New England Journal of Medicine 376:26 2513-2522.

9. Dresel, P. Evan and Arthur W. Rose. 2010. Chemistry and Origin of Oil and Gas Well Brines in Western Pennsylvania. Prepared for Pennsylvania Department of Conservation and Natural Resources. Open-File Report OFOG 10-01.0 2010.

10. Eckstein, Yoram. 2010. Is use of oil-field brine as a dust-abating agent really benign?

11. Tracing the source and flow path of contamination by oil brine in a shallow phreatic aquifer. Environ Earth Sci (2011) 63:201-214. DOI 10.1007/s12665-010-0689-x.

12. Farmer, Andrew M. 1993. The Effects of Dust on Vegetation-A Review. Environmental Pollution 79 (1993) 63-75.

13. Fayun Li, Ying Zhang, Zhiping Fan and Kokyo Oh. 2015. Accumulation of De-icing Salts and Its Short-term Effects on Metal Mobility in Urban Roadside Soils. Bull Environ ContamToxicol (2015) 94:525-531. DOI 10.1007/s00128-015-1481-0.

14. Ghio, Andrew J., Suryanaren T. Kummarapurugu, Haiyan Tong, Joleen M. Soukup, Lisa A. Dailey, Elizabeth Boykin, M. Ian Gilmour, Peter Ingram, Victor L. Roggli, Harland L. Goldstein, and Richard L. Reynolds. 2014. Biological effects of desert dust in respiratory epithelial cells and a murine model. Inhalation Toxicology 26(5): 299-309. DOI: 10.3109/08958378.2014.888109.

15. Goodrich, Betsy A., Ronda D. Koski, and William R. Jacobi. 2009. Conditions of Soils and Vegetation Along Roads Treated with Magnesium Chloride for Dust Suppression. Water Soil Air Pollution (2009) 198:165-188. DOI 10.1007/s11270-008-9835-4.

16. Graber, Kayla, Christina L. M. Hargiss, Jack E. Norland and Thomas DeSutter. 2017. Is Oil-Well Produced Water Effective in Abating Road Dust? Water Air Soil Pollut (2017) 228: 449https://doi.org/10.1007/s11270-017-3640-X. 
17. Greeman, Daniel J., Arthur W. Rosea, John W. Washington, Robert R. Dobos, and Edward J. Ciolkosz. 1999. Geochemistry of radium in soils of the Eastern United States. Applied Geochemistry 14 (1999) 365-385.

18. Greening, Tony. 2011. Quantifying the Impacts of Vehicle-Generated Dust: A Comprehensive Approach. The International Bank for Reconstruction and Development/The World Bank. $1818 \mathrm{H}$ Street NW, Washington, D.C. 20433. Accessed 20 February 2018 at http://documents.worldbank.org/curated/en/325581468161082361/Q uantifying-the-impacts-of-vehicle-generated-dust-a-comprehensiveapproach.

19. Herrold, Jeffrey E. 1984. The Use of Oil Field Brine on Michigan Roadways. Geological Survey Division, Michigan Department of Natural Resources. Accessed21 February 2018 at http://www.michigan.gov/documents/deq/Oil_Field_Brine_306996_7 .pdf.

20. Hiki, Kyoshiro and Fumiyuki Nakajima. 2015. Effect of salinity on the toxicity of road dust in an estuarine amphipod Grandidierella japonica. Water Science and Technology. 72.6 1022-1028. doi: 10.2166/wst.2015.304.

21. Irwin, Roy J., Mark van Mouwerik, Lynette Stevens, Marion DublerSeese, and Wendy Basham. July 1, 1997. Diesel Oil Entry Environmental Encyclopedia. Prepared for Water Resources Divisions, Water Operations Branch, National Park Service, Fort Collins, Colorado. Accessed 20 February 2018 at https://nature.nps.gov/hazardssafety/toxic/diesel.pdf.

22. Kirchner, Henry and James A. Gall. 1991. Liquid Calcium Chloride for Dust Control and Base Stabilization of Unpaved Road Systems. Transportation Research Record. 1291: 173178.onlinepubs.trb.org/Onlinepubs/trr/1991/1291vol1/1291-059.pdf.

23. Lauer, Nancy E., Nathaniel R. Warner, and Avner Vengosh. 2018. Sources of Radium Accumulation in Stream Sediments near Disposal Sites in Pennsylvania: Implications for Disposal of Conventional Oil and Gas Wastewater. Environ. Sci. Technol., Just Accepted Manuscript • DOI: 10.1021/acs.est.7b04952 • Publication Date (Web): 04 Jan 2018 Downloaded from http://pubs.acs.org on January 21, 2018.

24. Luttig, Stephen D. and Larry Weinstock 1998. U.S. Environmental Protection Agency memorandum dated February 12, 1998 on "Use of Soil Cleanup Criteria in 40 Part 192 as Remediation Goals for CERCLA Sites." EPA 540-F-97-0332, OSWER 9200.4-25. Accessed 
at https://www.epa.gov/superfund/radiation-superfund-sites\#arars on 20 February 2018.

25. Moore, James W. and Robert C. Welch. 1977. Environmental Aspects of Brine Usage for Highway Purposes. College of Engineering, University of Arkansas, Highway Research Project 44, Arkansas State Highway and Transportation Department.

26. Moritis, Guntis. 2004. Producing the third phase. Oil \& Gas Journal; Feb 23, 2004; 102, 8; 15.

27. Moses, P.J. 1981. "An Environmental Review of Calcium Chloride in Road Dust Control and Stabilization Applications," The Dow Chemical Company, June 1981.

28. Nelson, SS., D. R. Yonge, and M. E. Barber. 2009. Effects of Road Salts on Heavy Metal Mobility in Two Eastern Washington Soils. J. Environ. Eng., 2009, 135(7): 505-510 DOI: 10.1061/_ASCE_07339372_2009_135:7_505.

29. Norrstrom, A.-C. and E. Bergstedt. 2001. The Impact of Road DeIcing Salts $(\mathrm{NaCl})$ on Colloid Dispersion and Base Cation Pools in Roadside Soils. Water, Air, and Soil Pollution 127: 281-299.

30. Payne, Bryce F., Jr. 2018. Oil and Gas Well Brines for Dust Control on Unpaved Roads - Part 1: Ineffectiveness. European Scientific Journal September 2018 edition Vol.14, No.27 ISSN: 1857 - 7881 (Print) e - ISSN 1857- 7431. Doi:10.19044/esj.2018.v14n27p0. URL:http://dx.doi.org/10.19044/esj.2018.v14n27p0.

31. Poje, Gerald. 1986. Toxicological Analysis of Ohio Brine Constituents and Their Potential Impacts on Human Health. Prepared for the Governor's Oil and Gas Review Commission, Columbus, Ohio.

32. Pennsylvania Department of Environmental Protection 1993. "Summary of Pennsylvania Clean-up Standards for Hydrocarbon Contaminated Soils" in State Summary of Soil and Groundwater Cleanup Standards for Hydrocarbons 1993 accessed at https://nepis.epa.gov/Exe/ZyPURL.cgi?Dockey=9100MMZS.TXT.

33. Pennsylvania Department of Environmental Protection. 2010. Bureau of Waste Management. Management of Fill. Document number 2582182-773. Accessed at http://www.depgreenport.state.pa.us/elibrary/ (search by document number).

34. Pennsylvania Department of Environmental Protection. 2012. Closure Requirements for Underground Storage Tank Systems. Technical Guidance Number 263-4500-601. Accessed at http://www.dep.pa.gov/Business/Land/Tanks/Pages/DEP-TechnicalGuidance-Documents.aspx on 20 February 2018.

35. Pennsylvania Department of Environmental ProtectionEnvironmental Quality Board. 2016. Final Regulation \#3042 
Environmental Quality Board\#7-484: Environmental Protection Performance Standards at Oil \& Gas Well Sites.

36. Pennsylvania Department of Environmental Protection. October 1996. Non-Point Source Report on Roadspreading of Brine for Dust Control and Road Stabilization.

37. Ramakrishna, D.M. \& T. Viraraghavan. 2005. Environmental Impact of Chemical Deicers - A Review. Water Air Soil Pollut (2005) 166: 49. https://doi.org/10.1007/s11270-005-8265-9.

38. Rowan, E.L., M.A. Engle, C.S. Kirby, and T.F. Kraemer. 2011. Radium Content of Oil- and Gas-Field Produced Waters in the Northern Appalachian Basin (USA):Summary and Discussion of Data. Scientific Investigations Report 2011-5135.U.S. Department of the Interior--U.S. Geological Survey, Reston, Virginia.

39. Russell, David, and S. Charles Caruso. 1982. A Study of CostEffective Chemical Dust Suppressants for Use on Unpaved Roads in the Iron and Steel Industry. American Iron and Steel Institute, December 1982.

40. Skalak, Katherine J., Mark A. Engle, Elisabeth L. Rowan, Glenn D. Jolly, Kathryn M. Conko, Adam J. Benthem, and Thomas F. Kraemer. 2014. Surface disposal of produced waters in western and southwestern Pennsylvania: Potential for accumulation of alkali-earth elements in sediments. International Journal of Coal Geology 126 (2014) 162-170. http://dx.doi.org/10.1016/j.coal.2013.12.001.

41. Stogiannidis, Efstathios and Remi Laane. 2015. Source Characterization of Polycyclic Aromatic Hydrocarbons by Using Their Molecular Indices: An Overview of Possibilities. In D.M. Whitacre (ed.), Reviews of Environmental Contamination and Toxicology Volume 234. DOI 10.1007/978-3-319-10638-0_2.

42. Strong, Forrest C., 1944, "A Study of Calcium Chloride Injury to Roadside Trees," Quarterly Bulletin, Volume 27, Number 2, Michigan State College, Agricultural Experiment Station, pages 209 - 224.

43. Sullivan, John D. and Robert P. Graham. 1940. Effects of Exchangeable Bases on Torsion Properties of Clays. Journal of the American Ceramic Society 23(2) 39-51. DOI: 10.1111/j.11512916.1940.tb14197.x.

44. Tasker, T. L., W. D. Burgos, P. Piotrowski, L. Castillo-Meza, T. A. Blewett, K. B. Ganow, A. Stallworth, P. L. M. Delompré, G. G. Goss, L. B. Fowler, J. P. Vanden Heuvel, F. Dorman, and N. R. Warner. 2018. Environmental and Human Health Impacts of Spreading Oil and Gas Wastewater on Roads. Environmental Science \& Technology, 52 (12), pp. 7081-7091. DOI: 10.1021/acs.est.8b00716 
45. Trask, Parker D., and James EH Close. 1957. "Effect of clay content on strength of soils." Coastal Engineering Proceedings 1.6 (1957): 827-843.

46. University of Nebraska Environmental Health and Safety. 2003. Toxicology and Exposure Guidelines (Revised January 2003). University of Nebraska, Lincoln, Nebraska. Accessed at https://ehs.unl.edu/documents/tox_exposure_guidelines.pdf, 16 February 2018.

47. US Department of Transportation-Federal Highway Administration. August 2015. Gravel Roads Construction and Maintenance Guide.

48. USEIA 2016. Hydraulic fracturing accounts for about half of current U.S. crude oil production. Today in Energy, March 15, 2016. U.S. Energy Information Administration, Washington, D.C. Accessed at https://www.eia.gov/todayinenergy/detail.php?id=25372.

49. Veil, John A, Markus G. Puder, Deborah Elcock, and Robert J Redwick, Jr. 2004. A White Paper Describing Produced Water from Production of Crude Oil, Natural Gas, and Coal Bed Methane. Prepared by Argonne National Laboratory for U.S. Department of Energy - National Energy Technology Laboratory under Contract W31-109-Eng-38.

50. Warrence, Nikos J., James W. Bauder, and Krista E. Pearson. 2018. Basics of Salinity and Sodicity Effects on Soil Physical Properties. Land Resources and Environmental Sciences Department, Montana State University - Bozeman. Accessed 21 February 2018 at http://www.soilzone.com/Library/Salinity/Basics\%20of\%20salinity\% 20and\%20sodicity\%20effects.pdf.

51. Wise, Matthew E., Trudi A Semeniuk, RoelofBruintjes, Scot T. Martin, Lynn M. Russell, and Peter R. Buseck. 2007. Hygroscopic behavior of NaCl-bearing natural aerosol particles using environmental transmission electron microscopy. Journal of Geophysical Research, Volume 112, D10224, doi: 10.1029/2006JD007678, 2007.

52. Wyatt, T.A., J.H. Sisson, S.G. Von Essen, J.A. Poole and D.J. Romberger. 2008. Exposure to hog barn dust alters airway epithelial ciliary beating. European Respiratory Journal 31: 1249-1255. DOI: 10.1183/09031936.00015007. 